ORIGINAL ARTICLE

\title{
Timing of First Antenatal Care Visit and its Associated Factors among Pregnant Women Attending Public Health Facilities in Addis Ababa, Ethiopia
}

\author{
Hanna Gulema ${ }^{1}$, Yemane Berhane ${ }^{2}$
}

\footnotetext{
OPEN ACCESS

Citation: Hanna G, Yemane B. Timing of First Antenatal care visit and its associated factors among pregnant women attending public health facilities in Addis Ababa. Ethiop J Health Sci 2017;27(1):139.

http://dx.doi.org/10.4314/ejhs.v27i2.6.

Received: December 9, 2016

Accepted December 9, 2016

Published: March 1, 2017

Copyright: (C) 2015 Hanna G, et al. This

is an open access article distributed under

the terms of the Creative Commons

Attribution License, which permits

unrestricted use, distribution, and reproduction in any medium, provided the original author and source are credited.

Funding: Addis Continental Institute of

Public Health

Competing Interests: The authors

declare that this manuscript was approved

by all authors in its form and that no

competing interest exists.

Affiliation and Correspondence:

${ }^{1}$ Department of Public Health Science,

Addis Continental Institute of Public

Health, Addis Ababa, Ethiopia

${ }^{2}$ Department of Research and

Evaluation, Addis Continental

Institute of Public Health, Addis

Ababa, Ethiopia

*Email: hannagulema1@gmail.com
}

\begin{abstract}
BACKGROUND: Early initiation of antenatal care visits is an essential component of services to improving maternal and new born health. The Ethiopian Demographic and Health Survey conducted in 2011 indicated that only $11 \%$ of pregnant women start antenatal care in the first trimester. However, detailed study to identify factors associated with late initiation of care has not been conducted in Addis Ababa where access to health services is almost universal. The aim of this study was to assess the level of late first antenatal care visit and the associated factors.

METHODS: Facility based cross sectional study was conducted in public health centers in Addis Ababa. The health centers with experience of at least more than two years were selected randomly, one form each sub-city. The study subjects were pregnant women visiting the facilities for the first time during the index pregnancy. The study health centers were selected randomly from each subcity, and the study women were recruited consecutively until the required sample size was achieved. Data were collected using pretested questionnaire. Logistic regression analysis was done to identify factors associated with late ANC initiation.

RESULT: A total of 979 women participated in the study; 411(42.0\%; 95\% CI of 38.9\%, 45.1\%) of them came for their first ANC visit late, after 16 weeks of gestation. Wrongly perceived ANC initiation schedule was the strongest predictor of late initiation. After controlling for basic demographic and obstetric factors, the odds of starting the first antenatal care visit late was higher for women who did not know the antennal care initiation schedule correctly compared to women who knew the schedule correctly (AOR6.6; 95\% CI 3.03, 14.03).

CONCLUSION: Over 40\% of pregnant women do not initiate ANC visit in the first trimester largely due to lack of correct knowledge of the recommended ANC schedule.

KEYWORDS: Antenatal, Ethiopia, Initiation time
\end{abstract}




\section{INTRODUCTION}

The new model for antenatal care recommended by the World Health Organization (WHO) separates pregnant women into two groups: who are likely to need only routine antenatal care, which constitute about some $75 \%$ of pregnant women, and those with specific health conditions or risk factors who need special care and constitute about $25 \%$ of pregnant women $(1,2)$. However, the model recommends both groups of women to come as early as possible, before sixteen week of gestation. Early initiation of ANC visits enables health care providers to diagnose early pregnancy related complications and institute timely and appropriate interventions $(3,4)$.

Most women in sub-Saharan Africa, however, make their first ANC visits very late (511 , which ranges from $53 \%$ to $89 \%(12-17)$. Data from Ethiopia also show that about $83 \%$ of pregnant women nationally (18) and $59.8 \%$ of pregnant women in the capital city, Addis Ababa, initiate their first visits late (16).

The reasons for late initiation of ANC visit, although they vary a lot from context to context, include lack of awareness about the services (14), lack of women decision making power, unfavorable attitudes towards antenatal care services (19) and wrong perceptions about the purpose of the antenatal care services and their timing (20). Some of the wrong perceptions about the timing of ANC are related to the women's low educational status, lack of knowledge of ANC, and cultural and traditional beliefs related to health care seeking practices during pregnancy $(17,21-23)$.

Although late initiation of ANC visits by pregnant women in Addis Ababa is a wellrecognized challenge, studies to identify the factors associated with this practice are scanty. It is also imperative to conduct such kind of studies from time to time as the reasons for failure to initiate ANC early would not remain the same in a rapidly changing societal development. This study was conducted with the aim of identifying factors related to late ANC initiation.

\section{METHODS}

Study area: The study was conducted in Addis Ababa, the capital city of Ethiopia, with an estimated total population of 3.2 million. The city is divided into ten administrative units referred to as "sub-cities". There were 91 government health centers in the city that were more or less evenly distributed in the ten sub cities. In addition, there were 11 public hospitals, 33 private hospitals, 520 private clinics, 257 specialized clinics and 06 NGO clinics and health centers. Most health facilities in the city provide ANC services, but the standards vary remarkably. The public health facilities use the national guidelines for providing ANC services. The private facilities may not always follow the national guidelines (24).We conducted the study on public health centers that are supposed to be the first entry points for ANC according to the national guidelines.

Study design: Facility based cross sectional study design with internal comparison was conducted in health facilities in Addis Ababa in the year 2013.

Study participants: The study subjects were pregnant women who came for their first ANC visits in the selected health facilities during the study period, December 2013. Women who were seriously ill at the time of data collection and unable to give consent were excluded from the study.

Sample size: Sample size was determined using the formula for single population proportion: prevalence of first ANC initiation before $16^{\text {th }}$ weeks of gestation which is $40.2 \%$ was used to calculate the total sample size of 864 . Adding $10 \%$ allowance for nonresponse and refusal to participate, a total sample of 960 was required to determine the proportion of women who come late for their first ANC visits and to identify factors associated with late first visits. The total sample was divided into the selected ten health centers proportional to their monthly client loads.

Sampling procedure: A two-stage sampling procedure was used to select study subjects. First, one health center from each of the 10 sub-cities of Addis Ababa was selected using a simple random sampling procedure. Second, eligible pregnant women who came for their first ANC visits in the

DOI: http://dx.doi.org/10.4314/ejhs.v27i2.6 
selected health centers were enrolled continuously until the required sample size was achieved. Participants were allocated proportionate to the monthly ANC client load of eachselected health facility.

Data collection tools and procedures: Data were collected using structured questionnaire, which was developed based on the Ethiopian Demographic and Health Survey (DHS) data collection tool and other relevant literature. The questionnaire was first developed in English and later translated into Amharic. The information collected includes socio-demographic background of the mothers, obstetric history, past maternal service initialization and perception of ANC services.

Data collectors were nurses who received training on the objective of the study, interview technique and details of the questionnaire. Pretest was done in a public health center that was not selected for the study. Recruitment of the study participants was facilitated by ANC service providers in each study health center. The interview was conducted in Amharic. Eligible mothers were interviewed face-to-face at exist of ANC clinic.

In this study, late ANC initiation was defined as the first ANC visit made by pregnant women after 16 complete gestational weeks. Perceived time for initiating ANC was defined as what the women thought is the correct gestational age to initiate the first ANC visit.

Data quality assurance: To maintain the quality of data, the questionnaire was pretested in a similar level health facility which was not part of the study. After the pretest, some modifications were made on the questionnaire to improve the clarity of meanings. Data collectors were given orientation on the changes before the main study was conducted. Moreover, regular follow up was made by the principal investigator to monitor the data collection process. Furthermore, the collected data were checked regularly for their completeness and clarity, and feedbackwas given to the data collectors.
Data processing and analysis: double data entry procedure and data cleaning were done using EPI INFO version 3.5.1. Further data analysis was done using SPSS windows version 15.0 statistical software. The proportion and $95 \%$ confidence interval of the main outcome variable was calculated to show the extent of late initiation of ANC visit at the cutoff point of 16 weeks. The association of independent variables with late ANC initiation was examined by calculating the crude and adjusted odds ratios. Twelve variables were examined independently using a bivariate analysis, and those variables with a p-value of less than 0.20 were included into a logistic regression model to calculate the adjusted odds ratios and 95\% confidence intervals.

Ethical consideration: Ethical approval was obtained from Haramaya University and Addis Continental Institute of Public Health. Permission to carry out the study was granted from Addis Ababa Health Bureau. Individual informed verbal consent was obtained from each respondent after explaining the purpose of the study. Interviews were conducted in private space at the facility of the health center during exist from ANC services. Confidentiality was maintained by not recording identifying information and restricting access to data only to the research team.

\section{RESULT}

Socio-demographic background: A total of 997 pregnant women who came for their first ANC visits in the study health centers were enrolled into the study. The age of the respondents ranged from 16 to 39 years with mean $(+\mathrm{SD}) 25.81( \pm 4.149)$ years. Most respondents were married ,773(81.4\%), and about half had secondary level education ,484(50.9\%). Unemployment rate was $45.5 \%$, and $59.1 \%$ of the respondents had monthly income of less than 2000 Ethiopian Birr, which is equivalent to 100 United States Dollars (Table 1).

Prevalence of late ANC initiation: Among the 997 women, 411(42.0\%; 95\% CI of $38.9 \%$, $45.1 \%$ ) came late for their first ANC visits, after 16 weeks of gestation (Figure 1). The median time for the first visit was 16 weeks. 
Table 1: Profile of the study Participants in Addis Ababa, 2013.

\begin{tabular}{|c|c|c|c|c|c|}
\hline & Characteristics & $\begin{array}{c}\text { Total } \\
\text { Frequency }\end{array}$ & $\begin{array}{c}\text { Late (after } 16 \\
\text { weeks) } \\
\#(\%)\end{array}$ & $\begin{array}{c}\text { Early (at or } \\
\text { before } 16 \mathrm{wks}) \\
\#(\%)\end{array}$ & $\begin{array}{c}\text { Overall Percent } \\
\%\end{array}$ \\
\hline Age(Max:39) & $15-19$ & 58 & $32(55.2)$ & $26(44.8)$ & 5.9 \\
\hline \multirow[t]{4}{*}{$\mathrm{N}=990$} & $20-24$ & 321 & $133(41.4)$ & $188(58.6)$ & 33.0 \\
\hline & $25-29$ & 416 & $164(39.4)$ & $252(60.6)$ & 42.0 \\
\hline & $30-34$ & 144 & $61(42.4)$ & $83(57.6)$ & 14.9 \\
\hline & $35-39$ & 36 & $18(50.0)$ & $18(50.0)$ & 3.6 \\
\hline Ethnicity & Oromo & 202 & $83(41.4)$ & $119(58.9)$ & 20.8 \\
\hline \multirow[t]{4}{*}{$\mathrm{N}=987$} & Amhara & 426 & $176(41.3)$ & $250(58.7)$ & 43.9 \\
\hline & Tigre & 86 & $28(32.6)$ & $58(67.4)$ & 8.9 \\
\hline & Gurage & 179 & $86(48.0)$ & $93(52)$ & 18.4 \\
\hline & Others & 78 & $36(46.2)$ & $42(53.8)$ & 8.0 \\
\hline Marital status & Single & 56 & $20(37.7)$ & $33(62.3)$ & 5.7 \\
\hline \multirow[t]{2}{*}{$\mathrm{N}=991$} & Married & 918 & $382(42.2)$ & $524(57.8)$ & 92.6 \\
\hline & $\begin{array}{l}\text { Divorced or } \\
\text { widowed }\end{array}$ & 17 & $6(37.5)$ & $10(62.5)$ & 1.7 \\
\hline Religion & Orthodox & 651 & $264(41.1)$ & $379(58.9)$ & 65.5 \\
\hline \multirow[t]{4}{*}{$\mathrm{N}=994$} & Muslim & 198 & $90(46.9)$ & $102(53.1)$ & 19.9 \\
\hline & Protestant & 130 & $54(42.2)$ & $74(57.8)$ & 13.1 \\
\hline & Catholic & 10 & $2(20.0)$ & $8(80.0)$ & 1.0 \\
\hline & Others & 5 & $0(0.0)$ & $5(100)$ & 0.5 \\
\hline \multirow{3}{*}{$\begin{array}{l}\text { Mothers Education } \\
\mathrm{N}=992\end{array}$} & No formal & 114 & $60(54.5)$ & $50(45.5)$ & 11.5 \\
\hline & Education & & & & \\
\hline & $\begin{array}{l}\text { Primary and } \\
\text { above }\end{array}$ & 878 & $350(40.4)$ & $516(59.6)$ & 88.5 \\
\hline \multirow{3}{*}{$\begin{array}{l}\text { Husband Education } \\
\mathrm{N}=961\end{array}$} & No formal & 40 & $20(51.3)$ & $19(48.7)$ & 4.2 \\
\hline & Education & & & & \\
\hline & $\begin{array}{l}\text { Primary and } \\
\text { above }\end{array}$ & 921 & $377(41.5)$ & $532(58.5)$ & 95.8 \\
\hline \multirow{2}{*}{$\begin{array}{l}\text { Occupation } \\
\mathrm{N}=990\end{array}$} & Employed & 540 & $198(37.4)$ & $332(62.6)$ & 54.5 \\
\hline & Unemployed & 450 & $211(47.5)$ & $233(52.5)$ & 45.5 \\
\hline \multirow{3}{*}{$\begin{array}{l}\text { Income } \\
\mathrm{N}=880\end{array}$} & $<1000$ ЕTВ & 289 & $128(45.7)$ & $152(54.3)$ & 32.8 \\
\hline & 1001-2000 ЕТВ & 231 & $102(44.3)$ & $128(55.7)$ & 26.3 \\
\hline & $>2001 \mathrm{ETB}$ & 360 & $126(35.3)$ & $231(64.7)$ & 40.9 \\
\hline
\end{tabular}

Factors Associated with late ANC initiation: After adjusting for maternal age, maternal education, maternal occupation, average household income, parity, abortion, decision making ability and women's wrongly perceived ANC initiation schedule were the most strongly associated factors to late initiation (AOR6.6; 95\% CI 3.03, 14.03). Other factors like unemployment, average monthly income less than 2000 ETB, unplanned pregnancy and being free of pain during pregnancy were marginally associated with late initiation of ANC. Unemployed women are more likely to come late than employed women $(\mathrm{AOR}=1.4,95 \% \mathrm{CI}: 1.07,1.95)$. Similarly, women who had average household income less than two thousand Ethiopian Birr have more chance of coming late than those who had more $(\mathrm{AOR}=1.49,95 \%$ CI: 1.04,2.15) \& $\mathrm{AOR}=1.47,95 \%$ CI: $1.01,2.12)$.

Those having unplanned pregnancy also have higher chance of coming late than from those their

DOI: http://dx.doi.org/10.4314/ejhs.v27i2.6 
pregnancy is planned $(\mathrm{AOR}=1.5,95 \% \mathrm{CI}: 1.08$, 2.13), and those who are free of pain during pregnancy come late than who had pain or discomfort $(\mathrm{AOR}=1.54,95 \% \mathrm{CI}: \quad(1.08$, 2.18) (Table 2).

Table 2: Factors associated with first ANC initiation time among pregnant women use selected public primary health facility in Addis Ababa, 2013.

\begin{tabular}{|c|c|c|c|c|c|}
\hline \multirow[t]{2}{*}{ Variable } & & \multicolumn{2}{|c|}{$\begin{array}{l}\text { ANC Initiation time (gestational } \\
\text { week) }\end{array}$} & \multirow[t]{2}{*}{ COR (95\% C.I) } & \multirow[t]{2}{*}{ AOR (95\% C.I) } \\
\hline & & $\begin{array}{l}\text { Late (after } 16 \\
\text { weeks) } \\
\#(\%) \\
\end{array}$ & $\begin{array}{l}\text { Early }(\text { at or } \\
\text { before } 16 \mathrm{wks}) \\
\#(\%)\end{array}$ & & \\
\hline Maternal Age & $15-19$ & $55(50.5)$ & $54(49.5)$ & 1 & 1 \\
\hline \multirow[t]{4}{*}{$\mathrm{N}=990$} & $20-24$ & $159(58.9)$ & $111(41.1)$ & $0.71(0.45,1.11)$ & $0.74(0.44,1.24)$ \\
\hline & $25-29$ & $302(60.3)$ & $199(39.7)$ & $0.67(0.44,1.02)$ & $0.61(0.36,1.02)$ \\
\hline & $30-34$ & $33(55.9)$ & $26(44.1)$ & $0.80(0.43,1.52)$ & $0.79(0.36,1.72)$ \\
\hline & $35-39$ & $18(50)$ & $18(50)$ & $1.02(0.48,2.16)$ & $0.65(0.26,1.59)$ \\
\hline $\begin{array}{l}\text { Maternal Educational } \\
\text { status }\end{array}$ & $\begin{array}{r}\text { Primary and } \\
\text { above }\end{array}$ & $350(40.4)$ & $516(59.6)$ & 1 & 1 \\
\hline $\mathrm{N}=992$ & $\begin{array}{l}\text { No formal } \\
\text { Education }\end{array}$ & $60(54.5)$ & $50(45.5)$ & $1.77(1.18,2.63)$ & $1.14(0.66,1.94)$ \\
\hline Occupation new & Employed & $198(37.4)$ & $332(62.6)$ & 1 & 1 \\
\hline $\mathrm{N}=945$ & Unemployed & $211(47.5)$ & $233(52.5)$ & $1.52(1.18-1.962)$ & $1.45(1.07,1.95)^{*}$ \\
\hline \multicolumn{6}{|l|}{ Average House hold } \\
\hline Income & $>2001 \mathrm{ETB}$ & $126(35.3)$ & $231(64.7)$ & 1 & 1 \\
\hline \multirow[t]{2}{*}{$\mathrm{N}=880$} & 1001-2000ETB & $102(44.3)$ & $128(55.7)$ & $1.54(1.12,2.12)$ & $1.50(1.05,2.15)^{*}$ \\
\hline & $<1000 \mathrm{ETB}$ & $128(45.7)$ & $152(54.3)$ & $1.46(1.04,2.50)$ & $1.46(1.01,2.12)^{*}$ \\
\hline Parity & 0 & $192(40.0)$ & $288(60.0)$ & $0.82(0.63,1.05)$ & $0.87(0.62,1.21)$ \\
\hline $\mathrm{N}=985$ & $1 \&$ more & & & 1 & 1 \\
\hline Abortion & 0 & $338(43.4)$ & $440(56.6)$ & $1.35(0.98-1.86)$ & $1.43(0.98,2.09)$ \\
\hline $\mathrm{N}=997$ & 1 and more & $73(36.3)$ & $128(63.7)$ & 1 & 1 \\
\hline \multirow{3}{*}{$\begin{array}{l}\text { Perceived } \\
\text { initiation time } \\
\mathrm{N}=960\end{array}$} & At or before 16 & $347(39.3)$ & $537(60.7)$ & 1 & 1 \\
\hline & $\begin{array}{l}\text { weeks of } \\
\text { gestation }\end{array}$ & & & & \\
\hline & $\begin{array}{r}\text { After } 16 \text { weeks } \\
\text { of Gestation }\end{array}$ & $52(83.9)$ & $10(16.1)$ & $8.05(4.04,16.05)$ & $6.57(3.06,14.11)^{\ddagger}$ \\
\hline Planned pregnancy & Yes & $265(37.9)$ & $434(62.1)$ & 1 & 1 \\
\hline $\mathrm{N}=950$ & No & $145(52.5)$ & $131(47.5)$ & $1.81(1.37,2.40)$ & $1.52(1.08,2.14)^{*}$ \\
\hline Decision for the visit & $\mathrm{Me}$ & $235(38.9)$ & $369(61.1)$ & 1 & 1 \\
\hline \multirow[t]{3}{*}{$\mathrm{N}=989$} & My Husband & $137(46.1)$ & $160(53.9)$ & $1.34(1.02,1.78)$ & $1.13(0.79,1.59)$ \\
\hline & $\begin{array}{r}\text { Me and My } \\
\text { husband }\end{array}$ & $13(40.6)$ & $19(59.4)$ & $1.07(0.52,2.22)$ & $1.12(0.50,2.49)$ \\
\hline & $\begin{array}{l}\text { Other family } \\
\text { member }\end{array}$ & $23(56.1)$ & $18(43.9)$ & $2.01(1.06,3.79)$ & $1.16(0.52,2.58)$ \\
\hline Have pain currently & Yes & $92(37.1)$ & $156(62.9)$ & 1 & 1 \\
\hline $\mathrm{N}=950$ & No & $319(43.6)$ & $412(56.0)$ & $1.31(0.98,1.77)$ & $1.54(1.08,2.18)^{*}$ \\
\hline
\end{tabular}

${ }^{¥}$ significant at $\mathrm{p}<0.01 \quad$ *significant at $\mathrm{p}<0.05 \quad 1$ : reference category

\section{DISCUSSION}

In this study, about $42.0 \%$ pregnant women showed up late for their first ANC. WHO recommends that every pregnant woman start the first ANC visit before or at 16 weeks of gestation (1). This study indicated that a considerable proportion of pregnant women initiate their first

DOI: http://dx.doi.org/10.4314/ejhs.v27i2.6 
ANC visit after 16 weeks of gestation despite public health facilities provide free ANC services for all pregnant women. Pregenant women who had wrong perceptions about ANC schedule, unemployed, earning a monthly income less than two thousand Ethiopia Birr, whose pregnancy was unplanned and those free of pain or discomfort during pregnancy were more likely to initiate their ANC late. This finding is in congruent with most of other previous studies conducted in subSaharan Africa $(6-8,25,26)$.

Health centers were selected for the study because they are the first points of contact to maternal health services for the majority of pregnant women, and services are widely available and offered free of charges. Thus, selection biases that are due to accessibility and affordability of services can be avoided. The health centers have also improved their referral links to hospitals that can do operative interventions for complicated cases to increase the confidence of health providers at the facilities and the thrust of pregnant women (27). Thus, sampling from health center is likely to capture the majority of pregnant women in the city. However, economically better-off mothers are likely to use private maternal health facilities, and our findings may not represent that particular group of women.

The proportion of late ANC visit in this study is lower than previous reports from Ethiopia, which were $58.0 \%$ in Addis Ababa (16), 61.1\% in Mekelle (15), 64.6\% in Gondar (12) and 68.6\% in Kembata Tembaro (28). The observed difference could be due several factors. The most important factors are perhaps the improvements made in the maternal health services and the introduction of the Urban Health Extension program in Addis Ababa(29,30). Mothers residing in the city have access to better information regarding available services through health extension professionals, and geographic access to maternal health services is almost universal (18).

Our finding regarding the perceived timing of ANC visits was consistent with previous reports from the northwest part of the country, which also reported a strong association between perceived ANC schedule and timing of the first ANC visit(12). A study done in Nigeria also reported that the majority of mothers who come late for the first ANC visit thought that the second trimester is the ideal time for initiating ANC (17). Women initiate ANC visits late because they often perceive no benefit of booking in the first trimester (31) unless they experienced problems in previous pregnancies (20). Other reasons that curtail to early initiation of maternal health services include women's perception about service quality and some cultural beliefs concerning pregnancy and childbirth $(19,20)$.

Improving the delivery of essential information about ANC is critical to ensure that pregnant women maximally benefit from the services. Apart from the information provided through the healthcare providers, the health system needs to explore other alternative message delivery channels. Reaching women through their partners (23) and modern communication technologies such as SMS (32) can greatly improve the availability and reach of correct information (33). In addition, exploring the social diffusion approach involving family members, relatives and neighbors could help in disseminating maternal health information. The urban health extension professionals and the women health development army are the dominant grassroot level health cadres in Ethiopia (30). They too can be thought to use these methods to delivery timely information. Even traditional birth attendants and community representatives were effectively used in improving early booking for ANC in Tanzania (34). Above all, empowering women to freely utilize the information and access to maternal health service is critical (35).

In conclusion, $42 \%$ of pregnant mothers in the capital city of Ethiopia initiate the first ANC visit after 16 weeks of gestation, which is largely due to wrong perception of the correct timing of the first visit. Therefore, public education should be strengthened to change the women's perception about timing of ANC initiation.

\section{ACKNOWLEDGEMENTS}

We are highly grateful to Addis Continental Institute of Public Health for funding the research project. We thank the Addis Ababa City Adminstration Health Bureau for facilitating the

DOI: http://dx.doi.org/10.4314/ejhs.v27i2.6 
conduct of the study. We also thank the study participants, supervisors and data collectors.

\section{REFERENCES}

1. Villar J, Bergsjo P. WHO antenatal care randomized trial: Manual for the implementation of the new model. 2002;

2. AbouZahr C, Wardlaw T. Antenatal care in developing countries: Promises, achievements and missed opportunities-an analysis of trends, levels and differentials, 1990-2001. World Health Organization; 2003.

3. JHPIEGO/MNH Program. Focused Antenatal Care: Planning and Providing Care during Pregnancy. 2004 p. 2-4.

4. Villar J, Bergsjo P. WHO antenatal care randomized trial: Manual for the implementation of the new model. 2002.

5. I. Abou, Carla Lidia, Zahr, Wardlaw, Tessa M. Antenatal care in developing countries: promises, achievements and missed opportunities. WHO,UNICEF; 2003.

6. Tolera Gudissa Damme. Factors Associated With Late Antenatal Care Attendance among Pregnant Women Attending Health Facilities of Ambo Town, West Shoa Zone, Oromia Region, Central Ethiopia. Int J Med Pharm Sci. 2015;1(2):56-60.

7. Tesfalidet Tekelab, Balcha Berhanu. Factors Associated with Late Initiation of Antenatal Care among Pregnant Women Attending Antenatal Clinic at Public Health Centers in Kembata Tembaro Zone, Southern Ethiopia. Sci Technol Arts Res J Sci Technol Arts Res J. 2014;3(2):108-15.

8. Zeine Abosse, Mirkuzie Woldie, Shimeles Ololo. Factors Influencing Antenatal Care Service Utilization in Hadiya Zone. Ethiop $J$ Health Sci. 2010 ;20(2):75-81.

9. Girmatsion Fisseha GM, Mulu Tekie, Abraha W/Michael, Dejen Yemane, Tesfay Gerezigiher. Predictors of Timing of First Antenatal Care Booking at Public Health Centers in Mekelle City, Northern Ethiopia. $J$ Gynecol Obstet. 2015;3(3):55-60.

10. Ebeigbe PN, Ndidi EP, Igberase GO, Oseremen IG. Reasons given by pregnant women for late initiation of antenatal care in the niger delta, Nigeria. Ghana Med $J$. 2010;44(2):47-51.

11. Ivan Kisuule, Dan K Kaye, Florence Najjuka, Stephen K Ssematimba1, Anita Arinda, Gloria Nakitende, et al. Timing and reasons for coming late for the first antenatal care visit by pregnant women at Mulago hospital, Kampala Uganda. Kisuule Al BMC Pregnancy Childbirth. 2013;13(121):3-6.

12. Gudayu TW, Woldeyohannes SM, Abdo AA. Timing and factors associated with first antenatal care booking among pregnant mothers in Gondar Town; North West Ethiopia. BMC Pregnancy Childbirth. 2014;14:287.

13. Beauclair R, Petro G, Myer L. The association between timing of initiation of antenatal care and stillbirths: a retrospective cohort study of pregnant women in Cape Town, South Africa. BMC Pregnancy Childbirth. 2014;14:204.

14. Kisuule I, Kaye DK, Najjuka F, Ssematimba SK, Arinda A, Nakitende G, et al. Timing and reasons for coming late for the first antenatal care visit by pregnant women at Mulago hospital, Kampala Uganda. BMC Pregnancy Childbirth. 2013;13:121.

Belayneh T, Adefris M, Andargie G. Previous early antenatal service utilization improves timely booking: cross-sectional study at university of Gondar hospital, northwest Ethiopia. J Pregnancy. 2014; http://dx.doi.org/10.1155/2014/132494

16. Tariku A, Melkamu Y, Kebede Z. Previous utilization of service does not improve timely booking in antenatal care: cross sectional study on timing of antenatal care booking at public health facilities in Addis Ababa. Ethiop J Health Dev. 2010;24(3):226.

17. Gopakumar A. Pattern and Determinants of Antenatal Booking at Abakaliki Southeast Nigeria. Ann Med Health Sci Res. 2013;3(1):132-134.

18. Central, Statistical Agency [Ethiopia]. Ethiopian Mini Demographic and Health Survey 2014. Addis Ababa, Ethiopia; 2014: 112.

19. The Maternal and Child HealthIntegrated Program (MCHIP). Cultural Barriers to Seeking Maternal Health Care in Ethiopia: A 
Review of the Literature. United States Agency for International Development (USAID); 2012.

20. Simkhada B Porter M, Teijlingen ER, Simkhada P. Factors affecting the utilization of antenatal care in developing countries: systematic review of the literature. $J A d v$ Nurs. 2008;61(3):244-60.

21. Fawole A.A, Akande T.M. Influence of maternal Age and Education on Antenatal Clinic Attendance In Ilorin,Nigeria. Centerpointscience Ed. 2003;11(1):65-72.

22. Abosse Z, Woldie M, Ololo S. Factors influencing antenatal care service utilization in hadiya zone. Ethiop $J$ Health Sci. 2010;20(2):75-82.

23. Asefa A, Beyene H. Awareness and knowledge on timing of mother-to-child transmission of HIV among antenatal care attending women in Southern Ethiopia: a cross sectional study. Reprod Health. 2013;10:66. doi: 10.1186/1742-4755-10-66.

24. Federal Democratic Republic of Ethiopia Minstry of Health. Health and Health Related Indicators,EFY 2007. Director of Policy and Planning, FMOH; 2008.

25. Serawit Yilala. Assesment of Late Initiation of Antenatal Care and Associated Factors Among Antenatal Care Attendees in Selected Health Centers of Addis Ababa, Ethiopia, 2015. Addis Ababa Univ. 2015;28-41.

26. Temesgen Worku Gudayu, Solomon Meseret Woldeyohannes, Abdella Amano Abdo. Timing and factors associated with first antenatal care booking among pregnant mothers in Gondar Town; North West Ethiopia. BMC Pregnancy Childbirth. 2014;14(287):3-6.

27. Federal Democratic Republic of Ethiopia Ministry Of Health. National Reproductive Health Strategy 2006-2015. Federal Democratic Republic of Ethiopia Ministry Of Health; 2006.
28. Tekelab T, Berhanu B. Factors Associated with Late Initiation of Antenatal Care among Pregnant Women Attending Antenatal Clinic at Public Health Centers in Kembata Tembaro Zone, Southern Ethiopia. Sci Technol Arts Res J. 2014;3(1):108-115.

29. Federal Democratic Republic of Ethiopia Minstry of Health. Health Sector Development Program II. Federal Democratic Republic of Ethiopia Minstry of Health; 2002.

30. Planning and Programming Department,FMOH. Health Sector Strategic Plan III. Federal Democratic Republic of Ethiopia Minstry of Health; 2005.

31. Ebeigbe PN, Ndidi EP, Igberase GO, Oseremen IG. Reasons given by pregnant women for late initiation of antenatal care in the niger delta, Nigeria. Ghana Med $J$. 2010;44(2):47-51.

32. Higgs ES, Goldberg AB, Labrique AB, Cook $\mathrm{SH}$, Schmid C, Cole CF, et al. Understanding the role of mHealth and other media interventions for behavior change to enhance child survival and development in low- and middle-income countries: an evidence review. J Health Commun. 2014;19 (Suppl 1):164-89.

33. Nurmatov UB, Lee SH, Nwaru BI, Mukherjee M, Grant L, Pagliari C. The effectiveness of mHealth interventions for maternal, newborn and child health in low- and middle-income countries: Protocol for a systematic review and meta-analysis. J Glob Health. 2014 ;4(1):010407. doi: 10.7189/jogh.04.010407.

34. Mushi D, Mpembeni R, Jahn A. Effectiveness of community based Safe Motherhood promoters in improving the utilization of obstetric care. The case of Mtwara Rural District in Tanzania. BMC Pregnancy Childbirth. 2010;10:14.

35. Portela A, Santarelli C. Empowerment of women, men, families and communities: true partners for improving maternal and newborn health. Br Med Bull. 2003;67:59-72. 